\title{
A Critical Review of the Business Agility Literature in the Advancement of Information and Communication Technology
}

\author{
Budi Setiawan*) \\ ${ }^{*}$ STIE Kesatuan Bogor. E-mail: budisetiawan@stiekesatuan.ac.id
}

\begin{abstract}
As a matter of fact, business world realities are like a wilderness. All existing business person must have a good adaptation in the business dynamic environment to successfully survive and gain a competitive advantage in this ecosystem. Those who will survive are those who smartly and nimble facing all the dynamics business challenges, optimizing all their strength to capture the opportunities and reducing the risk. Those who succeed will stay alive. The four literature discussed below were trying to reveal the phenomena about business and strategic agility, from the different point of view and approachment. I am going to describing and elaborating each of the articles and relate the relevance of the discussion progressively. Although each of these four article written by the expertise in the relevant discipline, it still an opportunities to find out the lack of the clearer discussion for further improvement.
\end{abstract}

Keywords: business agility, strategic agility, critical review

\section{Introduction}

We are now live in a digital world that everyone gets connected each other, every time and everywhere, just simply by the utilitarian function of the various device and personal computer. Each of us relatively so easy to find information about anything, just search on the internet, simply click the Google button on our device. The business platform, now entering the new challenging era, by shifting, integrating, or moving from conventional platform to digital platform, driven by the advancement of information and technology that is getting more sophisticated over time. This also creates a new business paradigm toward the changing of the nature of business competition, that getting more complicated, because it is not focusing on location-centric anymore. 


\section{New Business Paradigm in advancement of ICTs}

Heisterberg and Verma (2014) mentioned that the business now facing the new paradigm based on the advancement of information and technology, emerge the cloud computing, mobile, social media, video, and big data era. These five technological expansions nowadays are congregating to change the engines of contemporary business. Corporate must well be adapting to this technology advancement, to survive and then becoming a winner in the business competition. There is the new era to deliver the product to the consumer, create the consumer relationship, to achieve the long-term relationship that is customer loyalty. Interestingly, we must have business agility with strategic agility, to create competitive advantages in a digital era. Heisterberg and Verma (2014) define business agility as innovation through partnership or collaboration to be capable to do in advance the challenges and opportunities before they come about. Until this point, the explanation from Heisterberg and Verma (2014) is still too broad, it should be narrowed. Teece (2016) fulfilling its lack with mentioned that many dealings of agility in the management literature would give the impression to advocate that corporate ought to persistently work toward befall agile no matter the cost, preserving options accessible open all the time, retaining redundancy at all times, and hang around in a steady circumstances of uncompromising transformation.

The new business paradigm in advance of business technology mentioned by Heisterberg and Verma (2014) will create an innovative way to create business agility in order to have a sustainable competitive advantage. Business evolving in digital world undoubtful is needed to look at the challenges and opportunities in a digital environment that rapidly arise. The digital environment now has generated like a "perfect storm" for the corporation in order to create their business agility. Vagnoni and Khoddami (2016) mentioned the transformative nature that emerged in the advancement of a digital world, not just affecting the nature of business competition, shifted from conventional to digital. It is also affecting to change the fundamental business value-creation manner and firm performance measurement indicators.

\section{Critical Review}

This conceptual thought by Heisterberg and Verma (2014) need to be more enhanced, based on the phenomenon of advancement in information and technology that empowered us to accomplish most of our business functions and utilities slightly without being physically hand over on the spot. The new business paradigm in digital world not just focusing on the removal of barriers related to physical infrastructure. On the other hand, it helps a lot in an effort of cost reduction on business operation, not just locally but also globally. High level of 
disruption circumstances encompasses uncertainty and risks faced by the corporation; need to be strategically well prevented (Vagnoni and Khoddami, 2016). There's a quiet missing explanation of this concept is about uncertainty issue. Furthermore, it is more important for the corporation to do the right things rather than doing the things right. It is in line with the statement of Teece (2016) that the degree of uncertainty has boosted spectacularly, as an indicator of the global economy that becomes more sophisticated and dramatically integrated with one single connection.

Heisterberg and Verma (2014) clearly made an endeavor to highpoint set of circumstances of success and failure as guidance, specifically for business practitioners and commonly for readers from scholars of relevant discipline. The proponent from Heisterberg and Verma, (2014) further help to clear identification about in what stage we belong in this digital world, and then how to transforming it in to achieve competitive advantages through strategic agility involving the advancement of technology forces. Heisterberg and Verma (2014) conducting a concept of strategic agility, it comprises of strategic sensitivity, endive obligation or collective commitment and resource changeableness. Strategic agility in the digital world will be allowing the corporation to have the ability to generate various needs and want from the customer, make the decision faster, and been better to face the competition.

This concept needs to be a further explanation through strategic agility implementation in a case study. Unfortunately, Heisterberg and Verma (2014) did not provide it in their article, whether they conceptualization will run well in every type or scale of business? The concept proposed by Heisterberg and Verma, (2014) further explained by Vagnoni and Khoddami (2016), that a corporates strategic agility is how the corporation capable to manage astonishing changes and risks that could be faced by corporations. To handle the disruptive era in digital advancement properly, the corporation needs to strategically adaptable as they are operationally well-organized.

Arbussa, Bikfalvi and Marquès (2017) more concrete explaining about the implementation of the strategic agility and integrating it properly with business model innovation (BMI). Interestingly, they are linkages the strategic agility and business model innovation in the service sector business in Small Medium Enterprises (SME). They were trying to scrutinize the strategic agility from the managerial capabilities point of view, and then they relate it to organizational capabilities. I really appreciate the effort of Arbussa, Bikfalvi and Marquès (2017) to fill the gap about the implementation of strategic agility in small medium enterprises, that dominated by substantiation from large corporations with just a few exclusions. The strategic consideration is more precarious for small medium enterprises. It's because this kind of corporation possibly will deficiency some 
corporate resources that will empower this meta-capability. Providentially, agility is frequently needless in business atmospheres exposed simply to risk. Alternatively, it is crucial when opposing the deep vagueness and correlated threats and opportunities representative of nowadays innovation economy (Teece, 2016).

Arbussa, Bikfalvi and Marquès (2017) argued that organizational agility is a much-touted attribute and typically be considered righteous. Nevertheless, there are linked costs, and the current literature not able to clearly explain when is agility is desirable by the corporation, how about the nature of its fundamentals base, and how, in further been able to connect to the strategy. Small-medium enterprises (or well known as UKM) can be further ground-breaking than large companies. It's because the small medium enterprises have a more flexible organizational structure, not have a complicated bureaucratic structure and even feasible appearance with flatter organizational hierarchies. Moreover, the small medium enterprises are better proficient to fit and enhance rather than the bigger scale of business of corporations. As the small medium enterprises successfully implement change faster and then become a better corporation in order to detect and learn from the mistakes ever happen.

With the case study that has been conducted by Arbussa, Bikfalvi and Marquès (2017), they suggested that a dynamic view of strategic agility in the substance, that dissimilar fundamental capabilities are required at different strategic phases. This links through current literature that straightens out the micro-foundations of dynamic capabilities and then model this recursive course of action. Case study analysis by Arbussa, Bikfalvi and Marquès (2017) also revealed that strategic sensitivity is unearthed to be narrowly dependent on the manager as an individual actor. The kind of agility, that a business person in the small medium enterprises choose to construct it into their business organizations, and preserve should rely on their strategy and market positioning. In other words, if the corporation (in this case is small medium enterprises) have resilient dynamic capabilities, the corporation will be better at sensing evolving developments. Additionally, in that circumstances, the corporation will triumph agility with less of sacrifice, and as the outcome, it will make the corporation has sustainable business and even growth better (Teece, 2016).

\section{Conclusion}

Based on the extant literature, we know there's a fact that the strategic sensitivity is more precarious for small medium enterprises. The advance growth of information and technology should be used appropriately to achieve competitive advantage, even on the small scale of business. The market environment has changed radically, and the focus is now shifting from location- 
centric to customer-centric. Those who successfully adapt their business, to this new paradigm will have a strong business agility, supported by strategic agility to create competitive advantages.

\section{Refferences}

Arbussa, A., Bikfalvi, A., \& Marquès, P., (2017) "Strategic agility-driven business model renewal: the case of an SME", Management Decision, Vol. 55 Issue: 2, pp.271-293, doi: 10.1108/MD-05-2016-0355

Heisterberg, R., \& Verma, A. (2014). Creating business agility : how convergence of cloud, social, mobile, video, and big data enables competitive advantage. John Wiley \& Sons, Inc., Hoboken, New Jersey

Teece, D., Peteraf, M., \& Leih, S. (2016). Dynamic Capabilities and Organizational Agility: risk, uncertainty, and strategy in the innovation economy. California Management Review. 58 (4), Summer 2016

Vagnoni, E., \& Khoddami, S., (2016) "Designing competitivity activity model through the strategic agility approach in a turbulent environment", foresight, Vol. 18 Issue: 6, pp.625-648, doi: 10.1108/FS-03-2016-0012 